\title{
Implementing a Mobile Application News Tool for Disseminating Messages and Events of AlBuraimi University College
}

\author{
https://doi.org/10.3991/ijim.v12i7.9484 \\ Ghalyia ALFarsi $\left.{ }^{\bowtie}\right)$, Jasiya Jabbar, Maryam ALSinani \\ ALBuraimi University College, Oman \\ galfarsi@buc.edu.om
}

\begin{abstract}
Technology is developing and changing in every moment that all domains are patchy without it. Our research utilizes the current trends and technology to design and develop a mobile application for the all members of the college. The students are the fundamental members in the college and they are our targets. Mobile notification system is an emerging technology, which influence in solving various dimensions of life. The college announcements and events are disseminated to students and staff through circulars, notice boards, emails, etc. Our research was to employ mobile affinity of especially students who ignore the circulars and notifications in notice board. The tool may be installed from play store mobile. The tool supports the widely used mobile operating system like android and iphone. This tool helps and provides a flexible way for communication. It list all events and news at AlBuraimi University College (BUC) like announcement of training courses and scientific workshop or classes cancel and others events. It also helps in easy access of college portal for both students and staff. The evaluation held finds positive response towards the need of this mobile application. The result shows the interest and satisfaction of users with BUC NEWS mobile application tool.
\end{abstract}

Keywords-Mobile application, SQL, java programming, Android, IOS.

\section{Introduction}

Mobile is one of the most important technologies in today's industry. Mobile phones are efficient communication devices and make life easier. The importance and uses of mobile are inexplicable which include communication, storage, entertainment, application, etc. Mobile phone applications broaden the effectiveness of mobile phones. It is important in all areas of life, especially education; it is indispensable in education and in information system areas stated in [1] [2] [3] [4].

One of important tools in the education institute is the mobile. Sohail et al (2013) introduced mobile supported learning in an introductory programming course at BUC [2]. Almost all mobile applications include features and properties that keep the people enjoyed and thus mobile are indispensable and mandatory in today's fast running life. The use of mobile applications run the gamut, from utility, productivity, and navigation 
to entertainment, sports, fitness, and just about any others imaginable. The speed of using and the interface of the mobile which is easy to use and clear steps as the mobile will pay and use it is positive relationship[3]. The other application area of mobile is utilizing it to give alerts for news. The amount of consumer use of news alerts has increased in several states during the past three years[4][1] .

A mobile operating system is an operating system that is specifically designed to run on mobile devices such as mobile phones, smartphones, PDAs, tablet computers and other handheld devices. Some popular mobile operating systems are Android, Bada, Blackberry, iphone, Palm, Symbian, etc. Out of these mobile OSs, most of the mobiles use android and iphone operating system in this current generation. Because of this reason and as the interaction of it with the user is very easy and simple; we implemented our application in it. A study conducted by M. Al-Emran et al(2016) states that $99 \%$ students of universities in Oman and UAE have and use mobiles[5]. In this research, we develop an application that gives news of the college to all members in the college. The news will move from the website to fit to the user's screens directly at the same time.

This research is trying to identify the different technologies used in iphone and Android application development process and the need of it to be implemented in order to access a wide range of BUC-specific sources[1][3][6][7][2]. It offers a tactic on how to decide which part of news to use and which feature of application want to use. It provides most of the needs for students and members of BUC such as register in courses, calendar of the BUC, etc. This research demonstrates successful execution of mobile portal, which includes features that are commonly accessed across through the website of BUC. This research is to identify the use of iphone and android mobile programming software applications in BUC. Some of the uses of this application are to help the students and the users of BUC to receive the important news and information associated with BUC. The application also allow students or faculty to update their contact information using the BUC and to import any information that they need from this application to speed up the student learning [8][9] [13].

This paper comprises a number of sections. It starts with a literature review then the discussion of methodology used is included, followed by a description of analysis or pre-questionnaire, design and development and finally the evaluation of the system. The paper concludes with a summary of the research work, the limitations and future enhancement of the work.

\section{Literature Survey}

The current mode of conveying any news or information to the staff and students in BUC are emails and circular. One of the important tools in the educational domain in this generation is mobile as shown in the result of gulf university study. It states that $99 \%$ of the student has their own mobiles and utilize it for learning [2][6]. Moreover, BUC also incorporated smart board into their teaching and learning process[10] [11].

Now-a-days notification systems are widely used in telecommunication devices. It is becoming a very important and accepted trend in this generation. It helps in solving 
various problems in human life. Ahmad and Ricky in their research propose a system notification to support students for academic announcement in the campus environment. This system supports only android platform [12]. Risald, Suyoto and Albertus in their work designed a mobile application tool using user centered design which help deaf people to make medical emergency calls. It has icons which automatically connects to the nearest hospital without any audio communication [13]. A mobile application tool was also designed to show the relationship between performance in language and occurance of depression in secondary school students [14].

L.Ashwin Kumar, in his research provides the basis for design and development of mobile applications that aid news broadcast access and interactive virtual community services, based on open technologies such as Android, Java programming language and MySQL database, etc. The intent was to create an easy-to-use, mobile, expandable and flexible, interactive client-server solution, including a gateway to web content. It also compared between different types of interactive services and news accesses[6][7][15].

Android application techniques was utilized to implement mobile application portal that consists of features used in Eastern Michigan University. It provides approach to android development due to its single focus on the data and environment. However, due to certain vulnerability, Android Mobile EMU Portal allows only viewing the data from Banner and cannot write information to its table that is the user can view the list of the available classes but cannot register for them [1].

The majority of smartphone users $(69 \%)$ have downloaded at least one news app, but only $20 \%$ are using news apps on a weekly basis. NIC Newman (2018), in his research shows his survey states that in current generation, it is a crucial and critical period for most technology companies as they defend and fight the growing criticism against them about the journalism industry and the impact of technology in societies [16] [21].

The student's portals and students timetables and the limitation of BUC system to change in different environments is overcome in research[8]. In this, the students portal and available courses for each semesters that the student need to know was implemented in the application.

Based on the literature review, preliminary finding shows that there is no technology for notifications process of news in BUC. In this research BUC portal is also accessible along with the news alerts and notifications.

\section{$3 \quad$ Methodology}

ADDV framework was adopted to develop this mobile application tool. ADDV includes analysis, design, development and validation, See figure 1. 




Fig. 1. ADDV phases

\subsection{Participants}

A survey was conducted with 35 participations inside the college, their ages was between 20 to 45 years old. The participants included male and female academic staff, administrative staff, and students. The students participated was from Information Technology department of diploma level evening section, the course comp123. The survey strengthened the interest of using mobile application and, the urgency and necessity of such an application that will distribute direct news and information to their mobiles than the traditional mode of conveying messages see table 1 .

Table 1. Profile of Participants

\begin{tabular}{|l|c|c|c|c|}
\hline \multicolumn{1}{|c|}{ Members } & Male $/$ Female & Experiences & Age & No of participation \\
\hline Administrative & Male & 3 to 10 & 25 to 35 & 6 \\
\hline Administrative & Female & 3 to 10 & 25 to 35 & 5 \\
\hline Academic members & Male & 3 to 10 & 25 to 35 & 4 \\
\hline Academic members & Female & 3 to 10 & 25 to 35 & 4 \\
\hline Head of IT Dep. & Male & 10 & 42 & 1 \\
\hline Student & Male & 2 & 19 to 21 & 7 \\
\hline Student & Female & 2 & 19 to 21 & 8 \\
\hline & & & & 35 participation \\
\hline
\end{tabular}

\subsection{Analysis}

In the analysis phase, the analysis of present system and requirement elicitation are conducted. For understanding the present system and the requirements, we used interviews and questionnaires. Open interviews are conducted with a sample of students, academic and administrative staffs to study the drawbacks and to understand what they want in addition to overcome those drawbacks. A questionnaire was also distributed which includes five questions about the satisfaction of using emails to get important news and events notifications, how often they check emails, which mode they prefer- 
mobile application or emails, etc. The analysis supports the need of this application. The analysis result shown in table 2.

Table 2. Pre-questionnaire analysis and result

\begin{tabular}{|c|c|c|c|c|c|c|}
\hline \multicolumn{2}{|c|}{} & Q1 & Q2 & Q3 & Q4 & Q5 \\
\hline \multirow{2}{*}{ N } & Valid & 35 & 35 & 35 & 35 & 35 \\
\cline { 2 - 7 } & Missing & 0 & 0 & 0 & 0 & 0 \\
\hline \multirow{2}{*}{ Mean } & 1.8571 & 2.0000 & 1.7143 & 1.6000 & 1.6000 \\
\hline Median & 2.0000 & 2.0000 & 2.0000 & 1.0000 & 1.0000 \\
\hline Std. Deviation & 1.06116 & 1.00000 & .66737 & .81168 & .81168 \\
\hline Variance & 1.126 & 1.000 & .445 & .659 & .659 \\
\hline Range & 3.00 & 3.00 & 2.00 & 3.00 & 3.00 \\
\hline Minimum & 1.00 & 1.00 & 1.00 & 1.00 & 1.00 \\
\hline Maximum & 4.00 & 4.00 & 3.00 & 4.00 & 4.00 \\
\hline
\end{tabular}

\subsection{Design and Development}

The analysis survey supports the necessity of an application, which will ease the communication, and notification of important news and events of the college. Thus on the notion that the entities in college are not satisfied with the mode of communication using the regular tools (Email, Magazine or any traditional tools) and need for direct mobile tool to save the time and to be in the time of event or direct news, the new application was to be developed.

The application helps the students and employees to facilitate the process of obtaining news. The system is very user-friendly and does not have any complex aspects that confuse students or employees or any users. This application starts with mobile application interface, which include many features that make it easy to keep track with latest news of college. Figure 2 shows the mobile application design model.

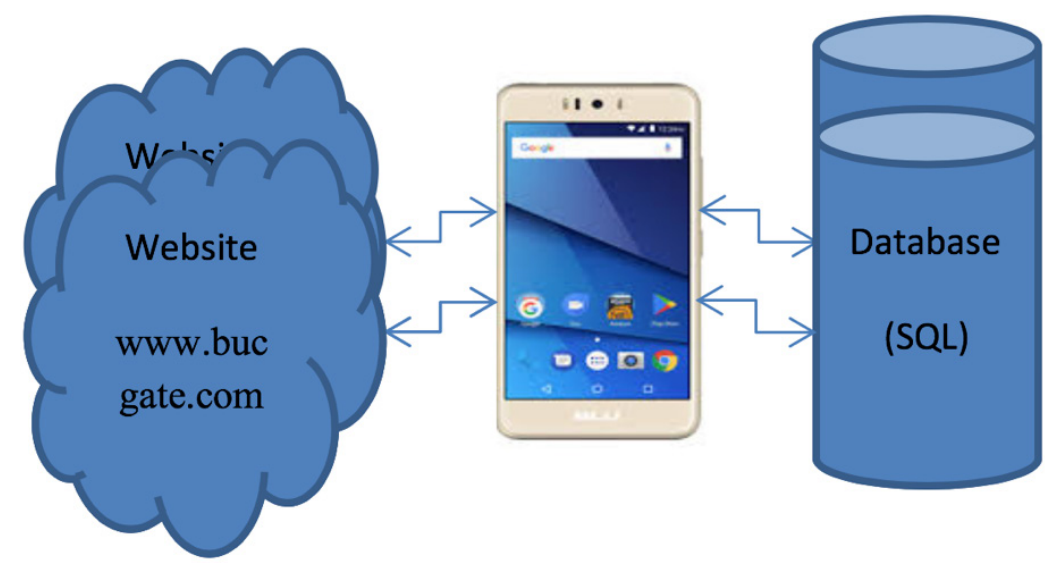

Fig. 2. Mobile application design model 
The GoDaddy is the hosting company that provides the website www.bucgate.com and database. The programming languages used in the website www.bucgate.com are php and html. For this application, we also used java, android studio and xcode.

The application provides us several functions. Firstly, it lists all the college news that can again be categorized and viewed. The different categories are general, sports, technics, training consultation, community service, and news related to different departments are grouped into law, business, student affairs, alumini, etc. Secondly, the application can be accessed in both English and Arabic. Thirdly, it provides an easy access to the portal for both the students and teachers. Students can view their schedule, results, register the courses form their mobile using this application.

The system mainly consists of three actors- admin, registered users and unregistered users. The admin can update all the news and make necessary changes. Only a registered user can make comments on the news. Any user can view the news and access portal evenif they have no user id and password. The users can add, modify or delete his/her comment that they add. And the users can control the notification accepted in their mobile, for example- if a student requires only news related to their major such as the student in information technology department only want the news of their major and may not want the news of business department or English department, they can disable the notifications. Thus, the users have a priority to select the news they want. Figures 3,4,5 and 6 show some of the windows of the application.

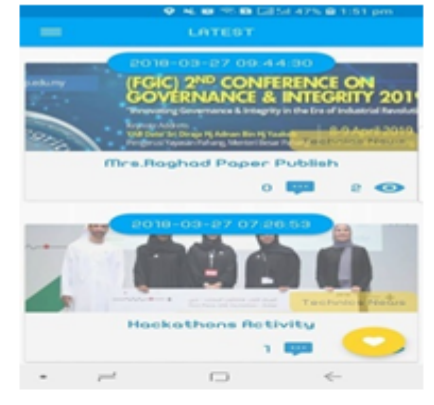

Fig. 3. Some news in the application



Fig. 5. Menu in application

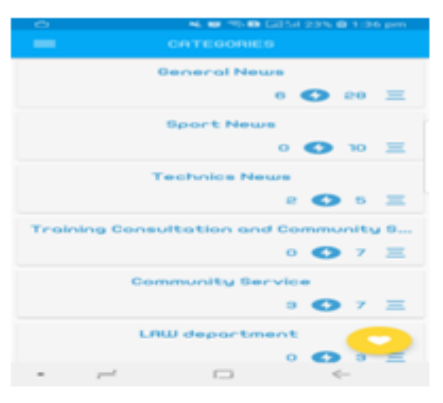

Fig. 4. Categories in the application

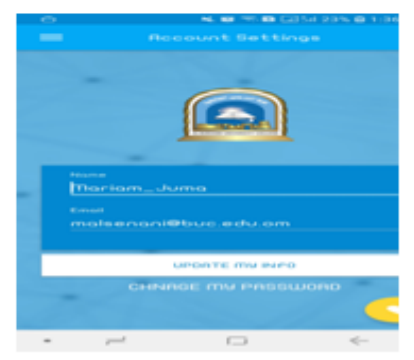

Fig. 6. Edit account 


\subsection{Verification}

The application is available in play store of mobiles. A sample of students and teachers installed this application and used it for a couple of period. Then the post-questionnaire was distributed among them which includes questions like which one is better email or app, which one will you check regularly, do you like the interface,etc . They selected their choice from options like strongly agree, agree, neutral, disagree and strongly disagree. The post-questionnaire survey proves that the system fulfils the requirements of users. The statistical analysis of survey is shown in table 3 .

\section{$4 \quad$ Result and discussion}

The results of the survey are illustrated and the statistical analysis is given based on the SPSS software. Analysis methods include the mean, median, mode and deviation. There are many types of averages in statistics and one of them is the "mean" and the "median" which are the mid value. The recurring values are called the "mode". Standard deviation is a statistical dimension of the dispersion of a set of data from its mean.

The tables 3, 4 and 5 below shows the result of post-questionnaire that proves that all the students and users satisfy from this application.

Table 3. Post-questionnaire statistics

\begin{tabular}{|c|c|c|c|c|c|c|c|c|}
\hline \multicolumn{2}{|c|}{} & Q1 & Q2 & Q3 & Q4 & Q5 & Q6 & Q7 \\
\hline \multirow{2}{*}{ N } & Valid & 35 & 35 & 35 & 35 & 35 & 35 & 35 \\
\cline { 2 - 9 } & Missing & 0 & 0 & 0 & 0 & 0 & 0 & 0 \\
\hline Mean & 1.8000 & 1.7714 & 1.8286 & 1.6000 & 1.5714 & 1.6571 & 1.6857 \\
\hline Median & 1.0000 & 2.0000 & 1.0000 & 1.0000 & 1.0000 & 2.0000 & 2.0000 \\
\hline Mode & 1.00 & 2.00 & 1.00 & 1.00 & 1.00 & 2.00 & 2.00 \\
\hline Std. Deviation & .99410 & .68966 & 1.09774 & .73565 & .81478 & .59125 & .63113 \\
\hline Variance & .988 & .476 & 1.205 & .541 & .664 & .350 & .398 \\
\hline Minimum & 1.00 & 1.00 & 1.00 & 1.00 & 1.00 & 1.00 & 1.00 \\
\hline \multicolumn{2}{|c|}{ Maximum } & 4.00 & 3.00 & 4.00 & 3.00 & 4.00 & 3.00 & 3.00 \\
\hline
\end{tabular}

The Cronbach's alpha metric is used to measure the scale reliability. Table 4 shows the result of it. The alpha coefficient of the seven questions is 0.984 . As the coefficient is greater than .70, we can say that the items have relatively high internal consistency and the result is acceptable.

Table 4. Reliability Statistics

\begin{tabular}{|c|c|c|}
\hline Cronbach's Alpha & Cronbach's Alpha Based on Standardized Items & N of Items \\
\hline .961 & .961 & 7 \\
\hline
\end{tabular}


Table 5. Summary Item Statistics

\begin{tabular}{|l|c|c|c|c|c|c|c|}
\hline & Mean & Min & Max & Range & $\begin{array}{c}\text { Maximum / } \\
\text { Minimum }\end{array}$ & Variance & $\begin{array}{c}\text { No of } \\
\text { Items }\end{array}$ \\
\hline Item Means & 1.771 & 1.514 & 1.914 & .400 & 1.264 & .020 & 7 \\
\hline Item Variances & .803 & .610 & 1.087 & .477 & 1.782 & .022 & 7 \\
\hline $\begin{array}{l}\text { Inter-Item Covari- } \\
\text { ances }\end{array}$ & .715 & .547 & .867 & .320 & 1.585 & .010 & 7 \\
\hline $\begin{array}{l}\text { Inter-Item Correla- } \\
\text { tions }\end{array}$ & .896 & .797 & .983 & .186 & 1.233 & .003 & 7 \\
\hline
\end{tabular}

Cochran's test was conducted with the post-questionnaire data set. Table 6 shows the result of anova with cochran's test to check if the student are satisfied or not. The table shows that the cochran's Q was 13.821 and statistical significance value 0.032 . As statistical significance value is less than 0.05 , it means that all the students and users are satisfied from this application.

Table 6. ANOVA with Cochran's Test

\begin{tabular}{|c|c|c|c|c|c|c|}
\hline \multicolumn{2}{|c|}{} & Sum of Squares & df & $\begin{array}{c}\text { Mean } \\
\text { Square }\end{array}$ & Cochran's Q & Sig \\
\hline \multicolumn{2}{|c|}{ Between People } & 127.249 & 34 & 3.743 & & \\
\hline \multirow{2}{*}{$\begin{array}{l}\text { Within } \\
\text { People }\end{array}$} & Between Items & 2.106 & 6 & .351 & 13.821 & .032 \\
\cline { 2 - 7 } & Residual & 29.894 & 204 & .147 & & \\
\hline \multicolumn{2}{|c|}{ Total } & 32.000 & 210 & .152 & & \\
\hline
\end{tabular}

Grand Mean $=1.7020$

\section{$5 \quad$ Conclusion and Future Work}

This research was done to ease the method of communication between the college, staffs and students. This mobile application provides the users with notifications of messages, events and news. The application has various sectors, which shows news related to them, which includes sports, technics, training consultation, community service, and news related to different departments. The application provides an easy access to the college portal. The post-questionnnaire results show that the goal of this research is achieved. So no need to depend on circulars, emails, etc.

The only limitation that we can mention is that the sample was small compared to the whole college. It is implemented only for two operating systems namely iphone and android. The students we selected only include information technology students, not distributed to all students in others majors in the college. But even though it has these drawbacks, it shows news of whole college irrespective of major and stream. In future, we plan to enhance the application to support mobile operating systems other than iphone and android. We also plan to enhance and improve the categories of news. 


\section{$6 \quad$ References}

[1] N. and I. , "Development Techniques for Android Platform Mobile Device Application," 2012.

[2] A. Eldow, M. Shakir, m. Yahya Abdu, S. Iqbal and A. K.H. Muttar, "Exploring the Extent of ICT Role as a teaching Tool in the Public Universities of Khartoum State," Journal of Engineering and Applied Science, vol. 13, no. 15, 2018.

[3] A. Eldow, M. Shakir and m. Yahya Abdu, "Using Information Communication Technology as a Teaching tool in Sudanese Governmental Universities of Khartoum State," International Journal on Informatics Visualization, vol. 1, 2017.

[4] T. R. M, R. A. B and b. A. Arshah, "Assessing the Impact of Technology Learning and Assessment Method on Academic Performance," (EURASIA) Journal of Mathematics, Science and Technology Education, vol. 14, no. 6, 2018.

[5] M. Al-Emran and S. Malik, "The Impact of Google Apps at Work: Higher Educational Perspective. International," vol. 10, no. 4, 2016.

[6] K. D. Macaluso and H. Alan, "The Use of Mobile Apps to Enhance Student.," vol. 43, no. 1 , 2016.

[7] N. Newman, "Media Journalism and Technology Predictions," 2016 ..

[8] M. E. H. M. \&. S. K. Al-Emran, "Investigating attitudes towards the use of mobile learning in higher," 2016.

[9] L. A. Kumar, "Mobile Application for News and Interactive Services," vol. 2, no. 1, 2012.

[10] S. R. Burgess and A. B. Murray, "Use of traditional and smartphone app flashcards in an introductory psychology class.," vol. 13, 2015.

[11] G. ALFARSI, A. K. OMAR and M. ALSINANI, "A rule-based system for advising undergraduate students," vol. 95, no. 11, 2017.

[12] G. ALFarsi and M. ALSinani, "Developing a Mobile Notification System for AlBuraimi University College Students," vol. 1, no. 1, 2017.

[13] T. R. M., M. M. N and A. R. B. A, "Review on the Effect of Student Learning Outcome and Teaching Technology in Omani's Higher Education Institution's Academic Accreditation Process," in International Conference on Software and Computer Applications, 2018.

[14] I. Sohail, M. U. Chowdhury and O. K. Harsh, "Mobile devices supported learning for novice programmers," in Second International Conference on E-Learning and E-Technologies in Education (ICEEE), 2013.

[15] Paramasivam, Gurunathan, Manohar and I. Sohail, "Bringing Technology Into The Class Room: Receptivity And Satisfaction Level of Faculty Members Using Smart Board - An Experimental Study," in The 2nd International Conference on Applied Information and Communications Technology, 2014.

[16] A. Sanmorino and R. M. Fajri, "The Design of Notification System on Android Smartphone for Academic Announcement," vol. 12, no. 3, 2018.

[17] Risald, S. and A. J. Santoso, "Mobile Application Design Emergency Medical Call for the Deaf using UCD Method," vol. 12, no. 3, 2018.

[18] A. S. Z. K. A. E. and A. D. , "Mobile Assessment Procedures for Mental Health and Literacy Skills in Education," vol. 12, no. 3, 2018.

[19] "Mobile News Notifications," 2016.

[20] N. Newman, "News Alerts and the Battle for the Lockscreen," 2018.

[21] T. R. M, M. M. N. and A. R. B. A., "Technology Enhancement Learning Reflection on Improving Students' Satisfaction in Omani Universities," Advanced Science Letters, vol. 24, no. $10,2018$. 
Paper-Implementing a Mobile Application News Tool for Disseminating Messages and Events of...

[22] G. McLean, K. Al-Nabhani and A. Wilson, "Developing a Mobile Applications Customer Experience Model (MACE)-," Journal of Business Research, p. 325-336, 2018. https://doi.org/10.1016/j.jbusres.2018.01.018

[23] Joanna K. Law a, Parker A. Thome b, Brenessa Linde, "Student use and perceptions of mobile technology in clinical," The American Journal of Surgery, pp. 196-199, 2018.

[24] H. M. Ade Hikmat, "Smartphone Use and Multitasking Behaviour in a Teacher Education Program (TEP)," vol. 12, no. 2, 2018.

[25] E. E. Fezile Ozdamli, "Opinions of Teacher Candidates on the Usage of Mobile," vol. 12, no. 2, 2018.

[26] V. B. Chin Lay Gan, "Enhancing classroom interaction via IMMAP - An Interactive Mobile Messaging App," vol. 34, 2017.

[27] T.-H. C. Mu-Yen Chen, "Modeling public mood and emotion: Blog and news sentiment and socio-economic phenomena," no. 2017. https://doi.org/10.1016/j.future.2017.10.028

[28] B. Ankit Kumar Jain, "Rule Based Framework for Detection of Smishing Messeges in Mobile Enviroment," Kurukshetra,India, 2017.

[29] T. Svarre, "Designing a Mobile Application for Structured and Flexible Interview Data Collection in the Health Domain," vol. 12, no. 3, 2018.

[30] M. T. A. F. K. C. B. N. D. P. Ratih Kartika Dewi, "The Development of Mobile Culinary Recommendation System Based on Group Decision Support System," vol. 12, no. 3, 2018.

\section{$7 \quad$ Authors}

Ghalyia ALFarsi, Jasiya Jabbar, and Maryam ALSinani are with ALBuraimi University College, Information Technology, Oman (e-mails: galfarsi@buc.edu.om, jasiya@buc.edu.om,mjuma14@gmail.com)

Article submitted 04 September 2018. Resubmitted 15 October 2018. Final acceptance 20 October 2018. Final version published as submitted by the authors. 